DOI: https://doi.org/10.24867/14AM01Azinovic

\title{
ANALIZA I OSNOVE ZA PROJEKTOVANJE UREĐAJA ZA CEPANJE OGREVNOG DRVETA
}

\section{ANALYSIS AND BASICS FOR CHOPPING FIREWOOD MACHINE DESIGN}

\author{
Marko Azinović, Fakultet tehničkih nauka, Novi Sad
}

\section{Oblast - MAŠINSTVO}

Kratak sadržaj - Razvijanjem svih grana tehnike u cilju da se čoveku olakša svakodnevni život, došlo je do potrebe za uređajem za cepanje ogrevnog drveta. U ovom radu je projektovana jedna izvedba hidraulično pogonjenog uređaja za cepanje ogrevnog drveta. Izvršen je proračun i usvajanje komponenti hidrosistema, završni proračun kritičnih mesta na konstrukciji uređaja i formirana tehnička dokumentacija za izradu konstrukcije.

Ključne reči: Cepanje ogrevnog drveta, Cepač, Hidrostatički prenosni sistem, Noseća konstrukcija

\begin{abstract}
Due to technology development in facilitating the everyday life, a need has arisen to introduce a firewood chopping machine. This paper presents the construction of a hydraulically driven device for firewood chopping. The calculations and the hydrosystem components approvals, as well as the final projection of the critical construction spots and technical documentation have been completed.
\end{abstract}

Keywords: Firewood chopping, Chopper, Hydrostatic transmission system, Supporting construction

\section{UVOD}

Prva pojava sekire u Mesopotamiji oko 6000. godine p.n.e. smatra se za početak potreba čoveka za cepanjem drveta. Svako domaćinstvo ima potrebu za većom ili manjom količinom iscepanog ogrevnog drveta. Količina iscepanog ogrevnog drveta zavisi od vrste grejanja u domaćinstvu.

Sam posao cepanja drveta zahteva određenu ljudsku snagu, vreme, kao i fizičku sposobnost za ovakav vid posla. Stvari u ljudskom društvu su vremenom podložne promenama. U najvećem broju slučajeva te promene su tu kako bi olakšale život ljudima. Takav primer promene desio se i u alatu za cepanje ogrevnog drveta. Ručno cepanje drveta sekirom pored zahtevanja fizičke spretnosti može biti i opasno, moguće je da sama sekira spadne sa drške kao i da dođe do razletanja sitnih komada drveta.

Shodno tim otežavajućim okolnostima, ljudi su našli način da taj posao sebi olakšaju koliko god je to moguće, a to su postigli projektovanjem i konstruisanjem hidrauličnih mašina za cepanje ogrevnog drveta.

\section{NAPOMENA:}

Ovaj rad proistekao je iz master rada čiji mentor je bio dr Radomir Đokić, docent.

\section{PREGLED REŠENJA}

Ideja ovakvog uređaja jeste da se primeni mehanizam koji će delimično ili u potpunosti da zameni upotrebu čovekove snage.

$\mathrm{Na}$ tržištu se mogu pronaći različite izvedbe uređaja za cepanje ogrevnog drveta. Različite izvedbe se mogu podeliti prema [1]:

- položaju (vertikalni, horizontalni i kombinovani),

- reznom klinu (jednim sečivom, krst, višekraka zvezda itd.),

- pogonu (ručni, nožni, elektromotor, motor SUS i pomoću građevinskih mašina),

- prenosniku snage (često hidraulični, ređe mehanički),

- mobilnosti (fiksna, mobilna).

Izvedbe se dobijaju kombinovanjem različitih navedenih parametara.

\subsection{Usvajanje sopstvenog rešenja}

Rešenje koje će se dalje obrađivati je prema položaju rada horizontalan položaj mašine. Horizontalni položaj je izabran iz razloga kompaktnosti konstrukcije u odnosu na uređaj sa kombinovanim položajem i veće sigurnosti u odnosu na uređaj vertikalnog položaja cepanja ogrevnog drveta.

Primarni rezni klin je izabran u obliku krsta sa dve sečne ivice. Veća produktivnost za $100 \%$ u odnosu na rezni klin sa jednom sečnom ivicom, i jednostavnijom konstrukcijom prihvata reznog klina $\mathrm{u}$ odnosu na klin oblika višekrake zvezde.

Iz razloga što je izabran za prenos snage hidrostatički sistem za čije napajanje je potrebna energija, izbor pogona je sveden na dva tipa, elektromotorni i motorom SUS. Izabran je motor SUS, koji za istu snagu ostvaruje identično vreme ciklusa i silu na hidrocilindru, pored čega ima mobilnost.

\section{ANALIZA OPTEREĆENJA}

\subsection{Eksperimentalna ispitivanja alata}

Eksperimentom je izvršeno ispitivanje alata za cepanje drveta kako bi se došlo do okvirnih vrednosti sila potrebnih za cepanje nekoliko tipova drveta. Pre eksperimenta je obavljeno modeliranje alata koji je prikazan na slici 1 , odnosno urađen je model identičan alatu kakav bi se našao na samom uređaju. Iz zahteva da prečnik trupca koji se cepa na uređaju ne prelazi $300 \mathrm{~mm}$, alat je napravljen manje visine. Dimenzija vertikalne oštrice iznosi $200 \mathrm{~mm}$, dok ukupna širina alata iznosi $304 \mathrm{~mm}$. 
Alat za cepanje drveta na sebi mora imati pripremu za kačenje na kidalicu u vidu rupe sa navojem koja se na slici 1 nalazi sa gornje strane.

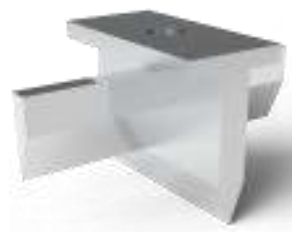

Slika 1. Ploča sa otvorom za prihvat alata u kidalici

\subsection{Rezultati eksperimenta}

Ispitivanje je obavljeno radi premalo sigurnih informacija (sile $F$ ) potrebnih samom projektovanju hidraulične mašine za cepanje ogrevnog drveta. Vrednosti koje su se mogle naći u dostupnoj literaturi ukazivale su na vrednosti $\mathrm{u}$ širokim granicama, koje nisu bile pouzdane za projektovanje hidrosistema mašine.

Kako se može videti na slici 2 eksperiment je izvršen sa četiri različita drvena panja. Alat koji je korišćen za eksperiment je identične konstrukcije kao što treba da bude na samom uređaju. Mašina na kojoj je vršeno ispitivanje jeste kidalica koja se nalazi u sastavu laboratorija proizvodnog mašinstva na Fakultetu tehničkih nauka u Novom Sadu.

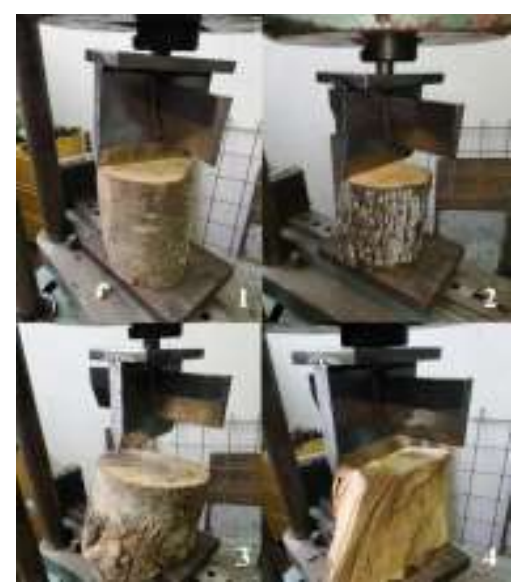

Slika 2. Panjevi na kojima je vršeno ispitivanje

Rezultati eksperimenta prikazani su u obliku dijagrama, gde je kao primer u ovom radu dat dijagram merenja (slika 3) za slučaj panja pod brojem 3 (slika 2), koji je zahtevao najveća opterećenja, tj. silu za cepanje. Sa prikazanog dijagrama može se lako pročitati da maksimalna sila koja je izmerena, nije prelazila $96 \mathrm{kN}$. Tako da je sila zaokružena i usvojena u iznosu od $100 \mathrm{kN}$ za dalji tok proračuna.

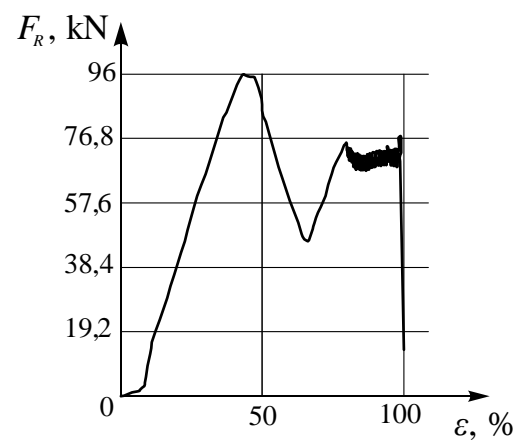

Slika 3. Dijagramski zapis rezultata pri merenju sa trećim panjem

\section{PRENOSNI SISTEM KOD UREĐAJA ZA CEPANJE DRVETA}

Potrebno je usvojiti varijantu hidrostatičkog prenosnog sistema za koji se formira funkcionalna hidraulična šema. Potrebno je izvršiti neophodne proračune za usvajanje elemenata hidrosistema.

\subsection{Formiranje funkcionalne šeme hidrosistema}

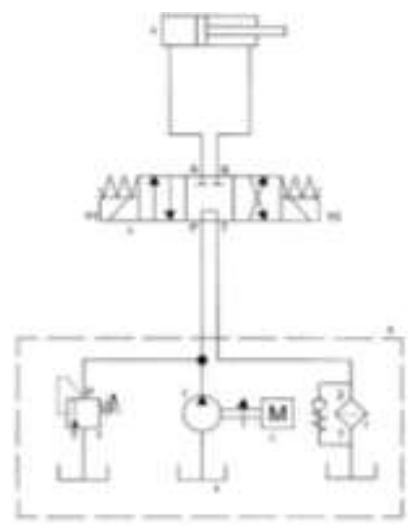

Slika 4. Prikaz funkcionalne šeme hidrosistema

$\mathrm{Na}$ formiranoj šemi mogu se videti komponente hidrosistema. Objedinjene komponente (8) uokvirene pravougaonikom (isprekidana linija) predstavljaju hidroagregat, koji objedinjuje više elemenata hidrosistema u jedan.

Ostale komponente hidrosistema:

(1) Motor SUS.

(2) Pumpa sa jednosmernim protokom, konstantne specifične zapremine.

(3) Direktno upravljani ventil za ograničenje pritiska.

(4) Rezervoar.

(5) Razvodnik 4/3, upravljan elektromagnetima. U neutralni položaj dovodi se silom opruga.

(6) Hidrocilindar dvosmernog dejstva sa jednom klipnjačom.

(7) Filter sa nepovratnim ventilom.

\subsection{Proračun elemenata hidrosistema}

U postavci zadatka dobijene su dimenzije trupca za koji je potrebno ostvariti cepanje. Daljim istraživanjem, kako je već rečeno u prethodnim tačkama, nisu bili dostupni dovoljno tačni podaci sile cepanja ogrevnog drveta, zbog čega je izvršen eksperiment. Eksperimentalno usvojena sila cepanja iznosi $F_{R}=100 \mathrm{KN}$. Pored ovih, potrebni su i sledeći podaci:

- Maksimalno vreme radnog hoda: $t_{\max }=10 \mathrm{~s}$,

- Hod klipa: $h=500 \mathrm{~mm}$.

\subsubsection{Proračun parametara hidrocilindra}

U prvom koraku izvršeno je usvajanje hidrocilindra odgovarajućih radnih parametara, čije je vrednosti neophodno proveriti (proračunati) sa stanovišta zadovoljavanja karakteristika navedenih kroz podatke $\mathrm{u}$ prethodnoj tački. Usvojen je hidrocilindar Prva petoletka V1 A 100/63/500, sledećih dimenzija:

- Prečnik klipa: $D=100 \mathrm{~mm}$,

- Prečnik klipnjače: $d_{k l}=63 \mathrm{~mm}$,

- Hod klipnjače: $h=500 \mathrm{~mm}$,

- Maksimalni radni pritisak: $p_{\max }=160$ bar. 
Na osnovu ulaznih podataka moguće je izračunati protok fluida koji iznosi [2]:

$$
\begin{aligned}
& Q_{c}=A_{k l} \cdot v_{1}=0,007854 \cdot 0,05=23,561 \frac{1}{\mathrm{~min}} \\
& A_{k l}=\frac{D^{2} \cdot \pi}{4}=\frac{0,1^{2} \cdot \pi}{4}=0007854 \mathrm{~m}^{2}
\end{aligned}
$$

gde je:

$A_{k l}$ - površina poprečnog preseka klipa koja predstavlja površinu kojom klip hidrocilindra potiskuje ulje prilikom radnog hoda,

$v_{1}$ - brzina kretanja klipa u radnom hodu.

Potreban pritisak hidrocilindra u radnom hodu:

$$
p_{c}=\frac{F_{R}}{A_{k l} \cdot \eta_{c}}=\frac{100000}{0,007854 \cdot 0,95}=131,5 \mathrm{bar}
$$

где је:

$$
\eta_{c}=0,91 \div 0,99 \text { - stepen korisnosti cilindra. }
$$

\subsubsection{Proračun parametara hidropumpe}

Za radne pritiske do 200 bar su u primeni zupčaste, a za radne pritiske do 400 bar su pak u primeni klipnoaksijalne pumpe. Kako je u prethodnoj tački izračunato da radni pritisak ne prelazi 200 bar, potrebno je usvojiti zupčastu pumpu.

Za usvajanje zupčaste pumpe potrebno je proračunati radnu zapreminu pumpe $\left(q_{P}\right)$, radni pritisak $\left(p_{r}\right)$ i broj obrtaja $\left(n_{m}\right)$ na vratilu pumpe, gde se primenjuje motor SUS sa brojem obrtaja $n_{m}=2000 \% \mathrm{~min}$.

$q_{P}=\frac{Q \cdot 1000}{n_{m} \cdot \eta_{v p}}=\frac{23,561 \cdot 1000}{2000 \cdot 0,94}=12,53 \mathrm{~cm}^{3} / \mathrm{o}$

gde je:

$\eta_{v p}$ - volumetrijski stepen korisnosti pumpe,

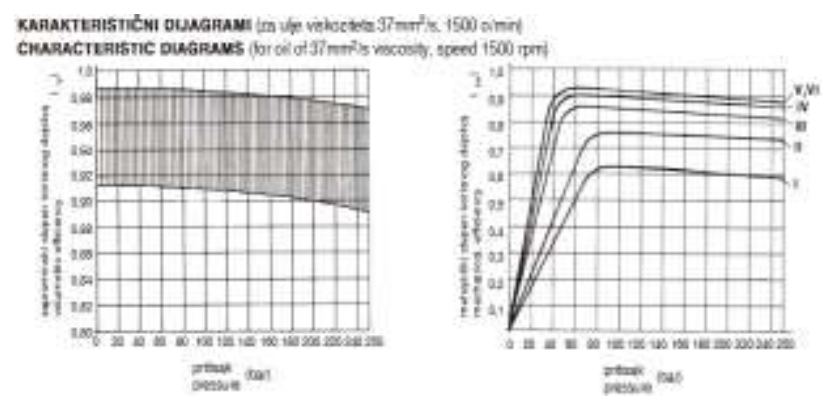

Slika 5. Dijagram za usvajanje zapreminskog $i$ hidromehaničkog stepena korisnosti

Radni pritisak zupčaste pumpe [3]:

$p_{r}=p_{c}+\Delta p_{1}+\Delta p_{f}=131,478+1,3+1,66 \approx 135 \mathrm{bar}$

Usvaja se zupčasta pumpa:

- Prva petoletka ZPB.476.28M

- Broj obrtaja: $n_{m}=2000 \% \mathrm{~min}$

- Broj obrtaja: $p_{n}=160$ bar

- Maksimalni pritisak: $p_{\max }=200 \mathrm{bar}$

- Radna zapreminina pumpe: $q=16 \mathrm{~cm}^{3} / \mathrm{o}$

Zbog usvojenih novih podataka pumpe došlo je do promene efektivnog protoka hidrosistema:

$$
Q_{e f}=\frac{q_{P} \cdot n_{m} \cdot \eta_{v p}}{1000}=\frac{16 \cdot 2000 \cdot 0,94}{1000}=30,08 \frac{1}{\mathrm{~min}}
$$

Usvojen je radni agregat "HONDA GX690" sa sledećim karakteristikama:

- Radna zapremina: $688 \mathrm{~cm}^{3}$,

- Maksimalna snaga motora: $15 \mathrm{~kW}$ pri $3600 \% \mathrm{~min}$,

- Maksimalni obrtni moment: 48,3 Nm pri $2500 \% \mathrm{~min}$,

- Sopstvena masa: $44 \mathrm{~kg}$,

- Sistem startovanja: Električno.

\section{PORVERA ČVRSTOĆE}

Cela metalna konstrukcija ovog uređaja se sastoji od glavnog nosača (IPB 200 profila) i postolja od cevi različitih profila. Glavni nosač u ovoj konstrukciji trpi dejstvo sile, kao i težinu hidrocilindra, potisnu ploču i rezni alat. U ovoj konstrukciji težina nabrojanih komponenti je zanemariva u odnosu na samu silu koja se ostvaruje, zbog toga će se provera čvrstoće računati samo na bazi sile koju ostvaruje hidrocilindar.

U toku radnog hoda hidrocilindra potisna ploča ostvaruje pritisak na drvo. Prilikom nailaska drvenog panja na rezni klin dolazi do ostvarivanja pritiska na potisnu ploču, pa samim tim i na nosač hidrocilindra i glavni nosač sa jedne strane, a sa druge strane preko reznog klina takođe na glavni nosač.

Za vreme radnog hoda postoje dva slučaja cepanja. Prvi slučaj je idealan kada drveni panj, svojim baznim površinama naleže pod pravim uglom na potisnu ploču i rezni alat. U ovom slučaju sila cepanja će biti u osi sa klipnjačom hidrocilindra. Najnepogodniji slučaj je kada dolazi do zakrivljenja panja tako da $\mathrm{u}$ tački dodiruje potisnu ploču i rezni klin, najudaljenije od glavnog nosača, slika 6 , pri čemu dolazi do povećanja momenta savijanja. Sa ovim slučajem će se vršiti provera čvrstoće.

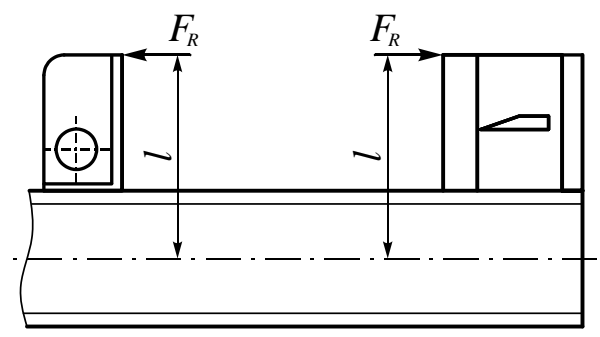

Slika 6. Najnepovoljniji proračunski slučaj pri cepanju drveta

\subsection{Kritični naponi}

Analizom konstrukcije uređaja jasno se mogu videti preseci koji su kritični i koji se moraju ispitati da li mogu da izdrže opterećenje usled cepanja drveta.

Presek A-A: Presek glavnog nosača između nosača hidrocilindra i reznog alata. Svi preseci između ove dve ravni imaju identično opterećenje.

Presek B-B: Presek potisne ploče neposredno iznad klipnjače, sa najvećim krakom u odnosu na tačku sile cepanja.

Presek C-C: Presek nosača alata neposredno iznad glavnog nosača. 
Presek D-D: Presek alata u vertikalnoj ravni upravno na osu glavnog nosača.

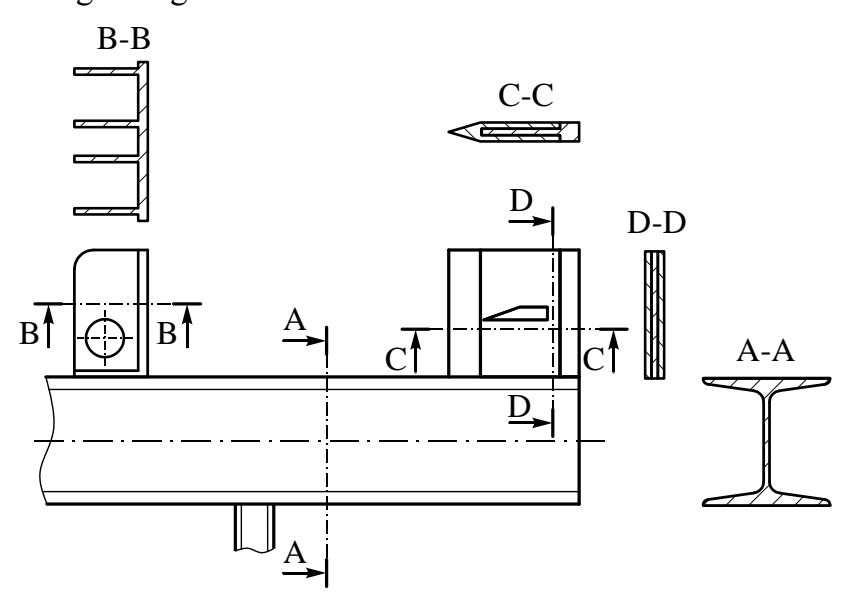

Slika 7. Kritični preseci

Završni proračun na kritičnim presecima je izvršen upoređivanjem izračunatih vrednosti napona za pomenute preseke sa dozvoljenim naponom.

Dozvoljeni napon za čelik S355, kojim je predviđena izrada konstrukcije je [4,5]:

$\sigma_{d o z}=\frac{R_{e H}}{v}=\frac{355}{1,5}=236,67 \mathrm{MPa}$

gde je:

$R_{e H}$ - granica razvlačenja za usvojeni materijal, $v=1,25 \div 1,5$ - stepen sigurnosti.

Presek A-A: Standardni profil IPB 200 opterećen momentom savijanja i aksijalnom silom.

Otporni moment preseka IPB 200 iznosi:

$W_{s A}=553 \mathrm{~cm}^{3}$

Moment savijanja profila usled sile $F_{R}$ i rastojanja $l$ sa slike 6:

$M_{s A}=F_{R} \cdot l=100 \cdot 30=3000 \mathrm{kNcm}$

Napon usled savijanja:

$\sigma_{s A}=\frac{M_{s A}}{W_{s A}}=\frac{3000}{553}=5,42 \mathrm{kN} / \mathrm{cm}^{2}=54,2 \mathrm{MPa}$

Napon usled aksijalne sile:

$\sigma_{a A}=\frac{F_{R}}{A_{A}}=\frac{100}{76,3}=13,1 \mathrm{kN} / \mathrm{cm}^{2}=131 \mathrm{MPa}$

gde je:

$A_{A}$ - površina poprečnog preseka A-A profila IPB 200

Ukupni napon iznosi:

$\sigma_{u k A}=\sigma_{s A}+\sigma_{a A}=54,2+131=185,2 \mathrm{MPa}<\sigma_{d o z}$

Presek B-B: Opterećen samo momentom savijanja.

Napon pri savijanju potisne ploče:

$\sigma_{s B}=\frac{M_{s B}}{W_{x B}}=\frac{1140}{126}=90,5 \mathrm{kN} / \mathrm{mm}^{2}=90,5 \mathrm{MPa}<\sigma_{d o z}$ gde je:

$M_{s B}$ - moment savijanja potisne ploče opterećen silom $F_{R}$ koja deluje sa krakom 11,4 cm na oslonac potiskivača:

$M_{s B}=F_{R} \cdot 11,4=100 \cdot 11,4=1140 \mathrm{kNcm}$
$W_{x B}$ - otporni moment za presek B-B.

$W_{x B}=\frac{I_{x B}}{y_{B \max }}=\frac{980,29}{7,78}=126 \mathrm{~cm}^{3}$

$y_{B \max }$ - najveća udaljenost unutar površine preseka od težišne tačke za ceo presek.

Presek C-C: Nosač je opterećen na savijanje.

Normalni napon od momenta savijanja iznosi:

$\sigma_{s C}=\frac{M_{s C}}{W_{x C}}=\frac{2000}{49,99}=40,008 \mathrm{kN} / \mathrm{cm}^{2}=400,08 \mathrm{MPa}>\sigma_{d o z}$

$M_{s C}$ - moment savijanja reznog alata opterećen silom $F_{R}$ koja deluje sa krakom $20 \mathrm{~cm}$ na oslonac reznog alata:

$M_{s C}=F_{R} \cdot l_{C}=100 \cdot 20=2000 \mathrm{kNcm}$

$W_{x C}$ - otporni moment za presek C-C.

$W_{x C}=\frac{I_{x C}}{y_{C \max }}=\frac{470,39}{9,41}=50 \mathrm{~cm}^{3}$

Presek D-D: Opterećenje u ovom preseku je od aksijalne sile na pritisak.

Normalni napon pri pritisku iznosi:

$\sigma_{p D}=\frac{F_{R}}{A_{D}}=\frac{100}{60}=1,67 \mathrm{kN} / \mathrm{cm}^{2}=16,7 \mathrm{MPa}<\sigma_{d o z}$

\section{ZAKLJUČAK}

Osnovni cilj rada bio je da se izvrše analize i postave osnove za projektovanje uređaja za cepanje ogrevnog drveta. U radu je izvršena analiza opterećenja koja se javljaju na reznom alatu prilikom cepanja i sprovedeni su svi neophodni proračuni za usvajanje komponenti hidrostatičkog prenosnog sistema. Eksperimentalno je utvrđena sila cepanja drveta. Sprovedeni su završni proračuni u kritičnim tačkama konstrukcije uređaja gde je zaključeno da su u preseku C-C naprezanja iznad dozvoljenih vrednosti. Konstrukciju u preseku C-C je potrebno izmeniti.

\section{LITERATURA}

[1] A. Jovičić, "Poboljšano rešenje hidrauličnog uređaja za cepanje ogrevnog drveta", Univerzitet u Novom Sadu, Fakultet tehničkih nauka, 2014.

[2] P. Malešev, "Hidroprenosnici u mehanizaciji”, Univerzitet u Novom Sadu, Fakultet tehničkih nauka, 2010.

[3] N.V. Kelić, "Hidroprenosnici", Univerzitet u Beogradu, Mašinski fakultet, 1989.

[4] R. Maretić, "Zbirka rešenih zadataka iz otpornosti materijala", Univerzitet u Novom Sadu, Fakultet tehničkih nauka, 2009.

[5] M. Ognjanović, "Mašinski elementi”, Univerzitet u Beogradu, Mašinski fakultet, 1999.

\section{Kratka biografija:}

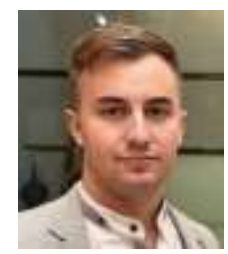

Marko Azinović rođen je 1996. godine u Beogradu. Master rad na Fakultetu tehničkih nauka iz oblasti Mašinstva odbranio je 2021. godine.

kontakt:2306996@gmail.com 